\title{
LITISCONSÓRCIO ATIVO NA RECUPERAÇÃO JUDICIAL
}

\author{
CO-PLAINTIGFF IN JUDICIAL REORGANIZATION
}

\author{
${ }^{1}$ Liliane Gonçalves Matos \\ ${ }^{2}$ Lívia Ximenes Damasceno
}

\section{RESUMO}

O objetivo deste estudo foi analisar a possibilidade de o grupo econômico formular um único pedido de recuperação judicial. Fez-se uso de uma pesquisa descritiva-analítica, analisando as doutrinas e jurisprudências sobre o assunto. Demonstrou-se que o processamento da recuperação em litisconsórcio ativo pode acarretar benefícios, visto que uma empresa do grupo pode a ajudar recuperar outra do grupo que esteja em crise, porém existe a possibilidade criar um incentivo negativo para o desenvolvimento da atividade empresarial globalizada. Concluiu-se que o litisconsórcio ativo na recuperação judicial é viável, todavia seria mais prudente que cada empresa do grupo apresentasse seu próprio plano.

PALAVRAS-CHAVE: Recuperação Judicial; Grupo Econômico; Litisconsórcio Ativo

\begin{abstract}
The aim of the study it was to analyze the possibility of the economic group file a single request for judicial reorganization. Concerning the methodology, the study is a descriptive analytic research, analyzing the legal doctrines and jurisprudence about the subject. It has been shown that the reorganization of groups, instead of separated companies may result benefits, as a company of the group can help to recover the others that are facing difficulties, but there is the possibility to create a negative incentive for the development of global business activity. It was concluded that the active joinder in bankruptcy is feasible, but it would be more prudent for each group company present its own reorganization plan.
\end{abstract}

KEY-WORDS: Judicial Reorganization; Economic group; Co-plaintiff

\footnotetext{
${ }^{1}$ Graduada em Direito pela Universidade de Fortaleza - UNIFOR, Ceará, CE, (Brasil). Advogada. Pós-Graduada em Direito e Processo Tributário e em Direito e Processo Empresarial, ambos pela UNIFOR. Mestranda em Direito Constitucional pela Universidade de Fortaleza - UNIFOR, Ceará, CE, (Brasil). E-mail: liliane.mat@hotmail.com.

${ }^{2}$ Graduada em Direito pela Universidade de Fortaleza - UNIFOR, Ceará, CE, (Brasil). Advogada. Professora e Coordenadora do Centro Universitário Christus - Unichristus, Ceará, CE, (Brasil). Mestre em Direito Empresarial pela Universidade de Coimbra - UC, Coimbra, (Portugal). E-mail: livia.ximenes@yahoo.com.br.
}

Revista Brasileira de Direito Empresarial -le-SSN: 2526-0235| Curitiba | v. 2 | n. 2 | p. 42 - 59 | Jul/Dez. 2016. 


\section{INTRODUÇÃO}

A recuperação de empresas, bem como a falência, é um instituto previsto na Lei $\mathrm{n}^{\circ}$ 11.101/2005. Esta é conhecida popularmente como Lei de Falência ou Lei de Recuperação de Empresa. Trabalhar-se-á, neste trabalho, ao se referir a essa lei com ambas as nomenclaturas, bem como com a abreviação LRE.

A recuperação tem por finalidade precípua a manutenção da empresa, ou seja, traz meios legais para viabilizar que uma atividade econômica que esteja passando por uma crise financeira continue funcionando. Têm-se três tipos de recuperação previstos no ordenamento jurídico brasileiro: a judicial, a extrajudicial e a especial. O objeto de estudo deste trabalho será apenas a recuperação judicial.

Atualmente, tem sido muito frequente o pedido de recuperação por mais de um devedor. Fundamentando-se tal pedido na caracterização de um grupo econômico, seja ele de fato, ou seja de direito, seria de fato aqueles que demonstrem a efetiva influência de uma sociedade nas decisões da outra, independentemente da existência de participação no capital social. Por outro lado, seria de direito os que possuem algum aspecto formal informando a formação do grupo, como um contrato.

A Lei de Falências, todavia, é omissa quanto ao cabimento ou não desse litisconsórcio. Em decorrência desta, surgem questionamentos sobre o procedimento que deverá ser seguido nos casos de grupos econômicos que passem por uma crise econômico-financeira, tais quais: deverá ser aceito ou não o litisconsórcio ativo no procedimento concursal? Sendo aceito, como deverá ser elaborado o plano de recuperação judicial? Será um para cada empresa do grupo econômico ou um único para todo o grupo?

$\mathrm{Na}$ busca de se responder a tais questionamentos, dividiu-se o presente trabalho em três capítulos. O primeiro tratará sobre a recuperação judicial, qual sua finalidade e quais suas principais características. No segundo, buscar-se-á trabalhar com o conceito de grupo econômico, bem como seus principais impactos na prática empresarial. Por fim, no último capítulo, estudar-se-ão os efeitos da recuperação judicial em grupos e far-se-á uma análise jurisprudencial do que tem sido decidido judicial sobre essa questão. 
A metodologia a ser utilizada basear-se-á em um estudo descritivo-analítico, desenvolvido por meio de pesquisa. O conhecimento, seja ele empírico, seja científico, é construído com o objetivo de ter uma compreensão melhor dos fatos e das descobertas do conhecimento. Traçar-se-á uma pesquisa qualitativa, ou seja, pesquisa subjetiva, seu critério não é numérico, há uma maior preocupação com o aprofundamento e a abrangência da compreensão das ações e das relações humanas, um lado não captável em equações, médias e estatísticas, ou seja, não quantificável, descrevendo, detalhadamente, situações que se adaptem ao objeto estudo. Será utilizada a pesquisa bibliográfica, pois explica um problema a partir de referências teóricas. Quanto aos objetivos, será constatada uma pesquisa descritiva, ou seja, descrever fenômenos, classificar e interpretar os fatos.

\title{
2 PERFIL DA RECUPERAÇÃO JUDICIAL
}

A finalidade primordial da recuperação judicial é conservar a atividade empresarial em funcionamento. O artigo 47 da LRE dispõe de forma expressa o objeto desse instituto, como pode se ver a seguir:

\begin{abstract}
A recuperação judicial tem por objeto viabilizar a superação da situação de crise econômico-financeira do devedor, a fim de permitir a manutenção da fonte produtora, do emprego, dos trabalhadores e dos interesses dos credores, promovendo, assim, a preservação da empresa, sua função social e o estímulo à atividade econômica.
\end{abstract}

Como se depreende do texto legal, esse empreendimento da manutenção da empresa visa não somente à conservação de determinada atividade empresarial, mas também à preservação dos empregos ligados àquela atividade. Entende-se que a empresa traz um bem à coletividade, não apenas ao empresário ${ }^{3}$. Em decorrência desse entendimento, existe, na Constituição Federal Brasileira, um princípio implícito, qual seja: o princípio de preservação da empresa. Sobre este, Mamede se pronuncia (2012, p.52):

Corolário do princípio da função social da empresa é o princípio da preservação da empresa, metanorma que é diretamente decorrente daquela anterior: é preciso preservar a empresa para que ela cumpra a sua função social. Pontua-se, assim, a existência de um interesse público na preservação da estrutura e da atividade empresarial (...). É incorreto compreender o princípio da preservação da empresa como uma afirmação absoluta de proteção ao patrimônio, aos interesses e aos atos do empresário ou da sociedade empresária por seus administradores e/ou sócios. Pelo contrário, a conservação da empresa deve ser pensada e considerada mesmo

\footnotetext{
${ }^{3}$ Ao se utilizar o termo empresário, neste trabalho, também estar-se-á englobando a sociedade empresária, ou seja, não está restrito ao âmbito do empresário individual.
}

Revista Brasileira de Direito Empresarial -le-SSN: 2526-0235| Curitiba | v. 2 | n. 2 | p. 42 - 59 | Jul/Dez. 2016. 
apesar de seu titular, quando isso se fizer necessário e, concomitantemente, juridicamente possível.

Não é qualquer empresa, entretanto, que terá direito a requerer a recuperação judicial. É necessário que se preencham determinados requisitos para se obter tal pedido deferido. É primordial, primeiramente, que o devedor tenha condições de se recuperar. Sabe-se que existem determinadas empresas que as dívidas são de tal monta que a sua recuperação é inviável, não existindo, assim, para ela, outra solução se não a falência. A Lei de Recuperação de Empresas prevê quais são os requisitos que o devedor deve preencher para pedir a recuperação judicial, quais sejam:

Art. 48. Poderá requerer recuperação judicial o devedor que, no momento do pedido,
exerça regularmente suas atividades há mais de 2 (dois) anos e que atenda aos
seguintes requisitos, cumulativamente: I - não ser falido e, se o foi, estejam
declaradas extintas, por sentença transitada em julgado, as responsabilidades daí
decorrentes; II - não ter, há menos de 5 (cinco) anos, obtido concessão de
recuperação judicial; III - não ter, há menos de 5 (cinco) anos, obtido concessão de
recuperação judicial com base no plano especial de que trata a Seção V deste
Capítulo; IV - não ter sido condenado ou não ter, como administrador ou sócio
controlador, pessoa condenada por qualquer dos crimes previstos nesta Lei. § $1^{\circ}$ A
recuperação judicial também poderá ser requerida pelo cônjuge sobrevivente,
herdeiros do devedor, inventariante ou sócio remanescente. (Renumerado pela Lei no
12.873, de 2013) § $2^{\circ}$ Tratando-se de exercício de atividade rural por pessoa
jurídica, admite-se a comprovação do prazo estabelecido no caput deste artigo por
meio da Declaração de Informações Econômico-fiscais da Pessoa Jurídica - DIPJ
que tenha sido entregue tempestivamente. (Incluído pela Lei no ${ }^{\circ} 12.873$, de 2013).

Assim, preenchendo o devedor esses requisitos, ele estará apto a requerer a sua recuperação judicial. Esse pedido somente pode ser feito pelo próprio devedor ${ }^{4}$, como se percebe na leitura desse artigo legal, ou seja, nenhum credor do devedor poderá formular um pedido de recuperação judicial em nome dele.

O procedimento básico, após o requerimento da recuperação judicial, é uma análise, pelo juiz, do efetivo preenchimento dos requisitos previstos no artigo 48 da LRE e a verificação da presença de todos os fatos e documentos necessários ${ }^{5}$ na petição inicial.

\footnotetext{
${ }^{4}$ Ressalta-se a hipótese dos sucessores previstas no $§ 1^{\circ}$ do artigo 48 da LRE, exposto acima.

${ }^{5}$ A relação do que deve acompanhar a petição inicial do pedido de recuperação judicial encontra-se no artigo 51 da LRE, que diz: Art. 51. A petição inicial de recuperação judicial será instruída com: I - a exposição das causas concretas da situação patrimonial do devedor e das razões da crise econômico-financeira; II - as demonstrações contábeis relativas aos 3 (três) últimos exercícios sociais e as levantadas especialmente para instruir o pedido, confeccionadas com estrita observância da legislação societária aplicável e compostas obrigatoriamente de: a) balanço patrimonial; b) demonstração de resultados acumulados; c) demonstração do resultado desde o último exercício social; d) relatório gerencial de fluxo de caixa e de sua projeção; III - a relação nominal completa dos credores, inclusive aqueles por obrigação de fazer ou de dar, com a indicação do endereço de cada um, a
} 
Estando em conformidade com o que exige a Lei, o juiz deferirá a recuperação judicial. Empós, o devedor deverá, impreterivelmente, no prazo de 60 (sessenta) dias, apresentar o plano de recuperação judicial.

\subsection{O Plano de Recuperação Judicial}

Tem-se o plano como a parte mais importante da recuperação judicial, visto que depende dele a realização dos objetivos próprios desse instituto. Se ele é elaborado de forma consistente, existem mais chances de a empresa conseguir, efetivamente, a almejada recuperação. No contrário, terá o devedor em crise apenas se limitado a cumprir papéis meramente processuais. Sabe-se que "não basta um plano bem elaborado para realizar-se a recuperação da empresa, há incidência de outros fatores econômicos, todavia um plano mal elaborado, sem dúvida, inviabilizará a superação da crise” (ULHOA, p.442-443).

O plano de recuperação judicial é de elaboração do próprio empresário, pois se entende que somente ele conseguiria saber o que de fato lhe ocasionou a crise e a maneira como superá-la. Ele terá ampla liberdade para fazer o plano ${ }^{6}$, apesar de que a LRE lhe traz

natureza, a classificação e o valor atualizado do crédito, discriminando sua origem, o regime dos respectivos vencimentos e a indicação dos registros contábeis de cada transação pendente; IV - a relação integral dos empregados, em que constem as respectivas funções, salários, indenizações e outras parcelas a que têm direito, com o correspondente mês de competência, e a discriminação dos valores pendentes de pagamento; V - certidão de regularidade do devedor no Registro Público de Empresas, o ato constitutivo atualizado e as atas de nomeação dos atuais administradores; VI - a relação dos bens particulares dos sócios controladores e dos administradores do devedor; VII - os extratos atualizados das contas bancárias do devedor e de suas eventuais aplicações financeiras de qualquer modalidade, inclusive em fundos de investimento ou em bolsas de valores, emitidos pelas respectivas instituições financeiras; VIII - certidões dos cartórios de protestos situados na comarca do domicílio ou sede do devedor e naquelas onde possui filial; IX - a relação, subscrita pelo devedor, de todas as ações judiciais em que este figure como parte, inclusive as de natureza trabalhista, com a estimativa dos respectivos valores demandados. $\S 1^{\circ}$ Os documentos de escrituração contábil e demais relatórios auxiliares, na forma e no suporte previstos em lei, permanecerão à disposição do juízo, do administrador judicial e, mediante autorização judicial, de qualquer interessado. $\S 2^{\circ}$ Com relação à exigência prevista no inciso II do caput deste artigo, as microempresas e empresas de pequeno porte poderão apresentar livros e escrituração contábil simplificados nos termos da legislação específica. $§ 3^{-} \mathrm{O}$ juiz poderá determinar o depósito em cartório dos documentos a que se referem os $\S \S 1^{\circ}$ e $2^{\underline{o}}$ deste artigo ou de cópia destes.

${ }^{6}$ Alguns créditos não podem ser previstos de forma absolutamente livre, ou seja, sofrem uma limitação, são os créditos trabalhistas e os decorrentes de acidente de trabalho. O artigo 54 da LRE assim dispõe: "O plano de recuperação judicial não poderá prever prazo superior a 1 (um) ano para pagamento dos créditos derivados da legislação do trabalho ou decorrentes de acidentes de trabalho vencidos até a data do pedido de recuperação judicial. Parágrafo único. O plano não poderá, ainda, prever prazo superior a 30 (trinta) dias para o pagamento, até o limite de 5 (cinco) salários-mínimos por trabalhador, dos créditos de natureza estritamente salarial vencidos nos 3 (três) meses anteriores ao pedido de recuperação judicial”.

Revista Brasileira de Direito Empresarial -le-SSN: 2526-0235| Curitiba | v. 2 | n. 2 | p. 42 - 59 | Jul/Dez. 2016. 
algumas sugestões de elaboração, em seu artigo 50, e discrimina, no artigo $53^{7}$, o que deverá nele conter.

Não são todos os créditos que poderão constar no plano, apesar da previsão da LRE no artigo 49, caput, dispor que "estão sujeitos à recuperação judicial todos os créditos existentes na data do pedido, ainda que não vencidos". Percebe-se, de logo, que todos os créditos que surgirem após a data do pedido não poderão constar no plano. Além disso, os parágrafos $3^{\circ} \mathrm{e}$ $4^{\circ}$ do mesmo artigo trazem exceções expressas sobre determinados créditos, quais sejam:

$\S 3^{0}$ Tratando-se de credor titular da posição de proprietário fiduciário de bens
móveis ou imóveis, de arrendador mercantil, de proprietário ou promitente vendedor
de imóvel cujos respectivos contratos contenham cláusula de irrevogabilidade ou
irretratabilidade, inclusive em incorporações imobiliárias, ou de proprietário em
contrato de venda com reserva de domínio, seu crédito não se submeterá aos efeitos
da recuperação judicial e prevalecerão os direitos de propriedade sobre a coisa e as
condições contratuais, observada a legislação respectiva, não se permitindo,
contudo, durante o prazo de suspensão a que se refere o $\S 4^{\circ}$ do art. $6^{0}$ - desta Lei, a
venda ou a retirada do estabelecimento do devedor dos bens de capital essenciais a
sua atividade empresarial. $§ 4^{0}$ Não se sujeitará aos efeitos da recuperação judicial a
importância a que se refere o inciso II do art. 86 desta Lei.

Dessa forma, os créditos acima especificados, com os créditos que vencerem após o pedido de recuperação, não poderão constar no plano. Muitas vezes, antes do pedido, é interessante que a empresa, que deseja requerer a recuperação, verifique quais são os tipos de débitos que mais possui e saiba se a recuperação judicial é, de fato, uma medida viável para sair da crise econômico-financeiro.

Após a elaboração e entrega ao Poder Judiciário, e serem cumpridas as devidas formalidades legais, como publicação, contagem de prazos, etc., o plano deverá ser votado em Assembleia $\mathrm{Geral}^{8}$ específica sobre esse assunto. Sobre esta, Mamede (2012, p.163) esclarece:

Não precisa ser uma reunião de única votação, na qual se questiona quem é favorável e quem é contra a aprovação. A própria Lei 11.101/05 deixa claro que o

\footnotetext{
7 Art. 53. O plano de recuperação será apresentado pelo devedor em juízo no prazo improrrogável de 60 (sessenta) dias da publicação da decisão que deferir o processamento da recuperação judicial, sob pena de convolação em falência, e deverá conter: I - discriminação pormenorizada dos meios de recuperação a ser empregados, conforme o art. 50 desta Lei, e seu resumo; II - demonstração de sua viabilidade econômica; e III laudo econômico-financeiro e de avaliação dos bens e ativos do devedor, subscrito por profissional legalmente habilitado ou empresa especializada. Parágrafo único. O juiz ordenará a publicação de edital contendo aviso aos credores sobre o recebimento do plano de recuperação e fixando o prazo para a manifestação de eventuais objeções, observado o art. 55 desta Lei.

${ }^{8}$ Em conformidade com o disposto no art. 55 da LRE, a assembleia somente é convocada caso algum credor manifeste uma objeção ao plano. Havendo objeção, a assembleia poderá aprovar, rejeitar ou aprovar com modificações o plano e deverá seguir os ditames dispostos no art. 45 da LRE.
}

Revista Brasileira de Direito Empresarial -le-SSN: 2526-0235| Curitiba | v. 2 | n. 2 | p. 42 - 59 | Jul/Dez. 2016. 
plano poderá sofrer alterações na assembleia geral, desde que haja expressão concordância do devedor e em termos que não impliquem diminuição dos direitos exclusivamente dos credores ausentes (art. 56, $3^{\circ}$ ) (...). A assembleia Geral para deliberação sobre o plano é - e deve ser - um espaço de negociação entre o devedor e os credores (...). Na busca de se atender aos objetivos listados no art. 47, pode-se mesmo deliberar a suspensão da assembleia para que as deliberações continuem em outra data, ou constituir grupo de trabalho, composto por devedor e credores, para afinar uma proposta que melhor possa atender as partes.

Sendo finalizadas as deliberações da assembleia geral, o plano, caso seja aprovado, deverá ser homologado pelo juiz, sendo concedida a recuperação ao devedor em crise econômico-financeiro, e este, conforme dispõe o art. 59, parágrafo $1^{\circ}$, da LRE, será considerado como título executivo judicial. Caso seja rejeitado, convola-se a recuperação judicial em falência, conforme prevê o artigo 73, inciso III, da LRE.

\title{
3 GRUPOS ECONOMÔMICOS
}

O direito empresarial sofreu profundas mudanças após a $2^{\mathrm{a}}$ Guerra Mundial. Juntamente com a globalização e as transformações sociais, eclodiu uma revolução tão profunda que alterou o modo de pensar os pilares societários, fazendo surgir uma nova forma de agrupamento societário. No mesmo sentido, escreve Lima e Miranda (2009, p.01):

\footnotetext{
No pós-guerra de 1939 - 1945, as circunstâncias econômicas, aliadas à globalização, bem como as profundas transformações sociais, trouxeram uma verdadeira revolução no campo do direito empresarial, com o desenvolvimento técnico das ideias dos grandes grupos de sociedade como consequência da concentração econômica das empresas modernas.
}

Essa revolução, chamada de a "Terceira Revolução Industrial", amparada pelo novo modo globalizado de pensar economia, encontrou um terreno propício para a fomentação de suas atividades, passando a ser o seu principal sustentáculo. Nesse sentido escreve Antunes (2005, p.35):

\begin{abstract}
A dinâmica do sistema económico e da sua célula básica, a empresa, não parou, porém, aqui. Numa confirmação inequívoca da "aceleração da história" do nosso tempo, o sistema económico concentracionístico, nascido nos finais do séc. XIX e sedimentado nos inícios do séc. XX, haveria de complexificar-se extraordinariamente a partir de meados deste século, com o advento da chamada Terceira Revolução Industrial: globalização da economia, eis a palavra-chave do novo sistema económico emergente em pleno dealbar do séc. XXI.
\end{abstract}

Assim, para Antunes (2005, p.35), a globalização propicia a "internalização e interdependência dos mercados nacionais, universalização do modelo de mercado livre, 
revolução tecnológica e das comunicações, aumento exponencial das barreiras ao comércio internacional". Ora a aglomeração das sociedades, dessa forma, deu-se de modo progressivo, visando a se amoldar às necessidades do mercado e diminuir os custos de transação.

É visando ao aperfeiçoamento mercantil e à diminuição dos riscos e custos da produção que as sociedades começam a se agrupar, transcendendo, inclusive, os limites territoriais das nações, fazendo surgir os grandes conglomerados multinacionais (SABAGE, 2010), de modo a buscar uma maior eficiência. Assim, tem-se que a globalização da economia foi e continua a ser um elemento fundamental na formação dos grupos societários, tendo em vista que a ampliação dos mercados, o consequente aumento do número de consumidores e o acirramento da concorrência tornaram necessária uma atuação empresarial agressiva, forte, tanto em capacidade financeira quanto tecnológica (HOLLANDA, 2008).

Essa evolução natural dos comportamentos comerciais, em especial aqueles atinentes ao direito societário, dá origem a uma nova roupagem societária: o grupo de sociedades. Apesar de ser uma evolução natural, a identificação dos grupos econômicos não é uma tarefa das mais fáceis, já que existem formas variadas para as sociedades empresárias manterem seus relacionamentos sem que se perca sua independência.

\title{
3.1 Elementos intrínsecos do grupo econômico
}

Os grupos têm sido identificados pelos jurisprudentes como sendo de fato ou de direito. Coelho, quando em parecer proferido às folhas 2594 a 2632 no Recurso Especial no 1.266.666 - SP (e-STJ, 2011, fl.14), afirma:

\begin{abstract}
Os grupos econômicos são tratados pela legislação interna dos diversos países que os reconhecem segundo dois amplos modelos: o modelo orgânico, segundo o qual o grupo é caracterizado mediante a análise de meras circunstâncias de fato que evidenciem a existência de direção econômica unitária para diversas sociedades formalmente autônomas; e o modelo contratual, segundo o qual, em vez disso, o grupo se formaria mediante um acordo expresso de vontades. O Brasil teria adotado o modelo contratual para a caracterização de um grupo econômico, de modo que sua caracterização, nos termos do art. 265 e seguintes da Lei das S.A., submete-se à convenção celebrada para sua caracterização, cuja celebração é regulada pelo art. 269 da mesma lei. Assim, no Brasil a caracterização do grupo econômico seria jurídica, não meramente fática.
\end{abstract}

Ainda nas palavras do autor do parecer supramencionado, ao continuar o seu raciocínio acerca da característica adotada para a identificação dos grupos sociais, ele acredita que,

Revista Brasileira de Direito Empresarial -le-SSN: 2526-0235| Curitiba | v. 2 | n. 2 | p. 42 - 59 | Jul/Dez. 2016. 
mesmo nos países de modelo contratual, seria possível identificar a coexistência de duas categorias: os grupos de fato e os grupos de direito 9 . Para ele, "embora elejam certas formalidades cujo cumprimento é indispensável à configuração jurídica do grupo, não se podem ignorar a existência de sociedades que, de fato, estão articulando seus esforços na realização de seus respectivos objetivos sociais sem o atendimento daquelas" (e-STJ, 2011, fl.2611). Um grupo de fato, assim, "seria aquele que atender às mesmas características de um grupo de direito, exceto as de ordem formal" (e-STJ, 2011, fl.2613). No mesmo sentido, a Ministra Nancy Andrighi escreve no voto do REsp no 1.266.666 - SP (e-STJ, 2011, fl.13):

\begin{abstract}
A coligação se caracteriza, essencialmente, na influência que uma sociedade pode ter nas decisões de políticas financeiras ou operacionais da outra, sem controlá-la. Antigamente, a Lei das S/A dispunha, em seu art. $243, \S 1^{\circ}$, acerca de um montante fixo para que fosse automaticamente caracterizada coligação entre empresas. Dizia que "são coligadas as sociedades quando um participa, com $10 \%$ (dez por cento) ou mais, do capital da outra, sem controlá-la". Esse percentual, contudo, era fixado para estabelecer, consoante a disposição contida no caput desse artigo, a obrigatoriedade de menção dos investimentos nessa sociedade no relatório anual da administração. Na prática, contudo, independentemente de um percentual fixo, o conceito de coligação está muito mais ligado a atitudes efetivas que caracterizem a influência de uma sociedade sobre a outra. Há coligação, por exemplo, sempre que se verifica o exercício de influência por força de uma relação contratual ou legal, e em muitas situações até mesmo o controle societário é passível de ser exercitado sem que o controlador detenha a maioria do capital social. Basta pensar, nesse sentido, na hipótese de uma empresa com significativa emissão de ações preferenciais sem direito a voto. (Grifo próprio).
\end{abstract}

Outro fator que deve ser levado em consideração nos grupos sociais é a forma como o poder de controle se manifesta. Para Berle e Means (1932, p. 216-217) “controle empresarial nada mais seria do que um bem social ou empresarial, cujo valor pertenceria, de conseguinte, à própria companhia, e não aos seus acionistas, individualmente considerados". Requião (1974, p.23), por sua vez, afirma que controle "deve ser considerado um bem imaterial ou incorpóreo, análogo ao aviamento da empresa, apropriável, por ocupação, pelo acionista ou pelo grupo que conseguir reunir a disposição do maior número de títulos".

\footnotetext{
${ }^{9}$ No Direito Comercial, o conceito de grupo econômico é objeto da lei das sociedades anônimas (Lei 6.404/76), a partir da interpretação coordenada de alguns dos seus dispositivos (arts. 265, 267, 269, etc.). Dessa forma, os grupos de direito somente podem ser formados mediante a celebração de uma convenção (contrato, claro) entre todas as sociedades participantes, cujo objetivo econômico específico estará em se obrigarem a combinar recursos ou esforços para a realização dos respectivos objetos, ou a participar de atividades ou empreendimentos comuns. Essa convenção para ter eficácia necessita ser aprovada pelas assembleias gerais ou reuniões de sócios de todas as sociedades que irão constituir o grupo. Além disso, é obrigatória a designação de uma sociedade controladora, ou de comando do grupo, necessariamente brasileira, que exerce, direta ou indiretamente, de modo permanente, o controle das sociedades filiadas, como titular de direitos de sócio ou acionista, ou mediante acordo com outros sócios ou acionistas.
} 
Pode-se afirmar que o controle é, portanto, o "poder de dispor dos bens alheios como proprietários. Controlar uma empresa significa poder dispor dos bens que lhe são destinados, de tal arte que o controlador se torna senhor de sua atividade econômica" (CHAMPAUD, 1965. p. 969). Desse modo, apresenta-se como elemento indissociável da natureza humana. Assim, entender as estruturas do poder de controle é de suma importância para compreender as decisões e o destino da pessoa jurídica (MATOS, 2014).

Para os grupos, por ser um conjunto de sociedades autônomas e independentes, o poder externo exercido pode ser por subordinação ou por coordenação. Os grupos de subordinação teriam uma estrutura piramidal, com uma sociedade exercendo o controle sobre as demais. Já no de coordenação, há apenas articulação de atividades e investimentos (e-STJ, 2011, fl. 2612).

A caracterização de grupo, todavia, repousa na característica essencial de combinação de esforços das sociedades para realização dos respectivos objetivos ou participação em atividades ou empreendimentos comuns (art. 265 da Lei das S/A). Assim, os grupos empresariais devem ser entendidos como aqueles caracterizados pela reunião de empresas por meio de um processo de concentração e sob uma direção comum, mas sem fusão de patrimônios nem a perda da personalidade jurídica de cada empresa integrante, pois os grupos de sociedade visam à concretização de empreendimentos comuns.

A jurisprudência pátria entende que haverá grupo econômico sempre que sobre uma empresa exista outra que exerça poder nas decisões políticas, financeiras ou operacionais sobre ela, sem controlá-la ou mesmo sem que, necessariamente, seja possuidora do capital social.

\subsection{Responsabilidades das Obrigações}

Tendo em vista a caracterização de um grupo econômico, um dos grandes problemas que se tem quando se começa a analisar a responsabilidade empresarial plurissocietária reside no fato de não se conseguir adequá-las ao regime geral de responsabilidades que tem como pilares a personalidade jurídica das sociedades e a limitação das responsabilidades dos sócios. Antunes endossa o questionamento ao discorrer (2008, p.38): 
O regime de responsabilidade da empresa plurissocietária constitui hoje a pedra de toque da regulação jurídica desta nova forma de organização empresarial, podendo afirmar-se existir mesmo um consenso neste ponto entre os juristas de ambos os lados do Atlântico: assim, se um dos mais reputados juscomercialistas da "Civil Law" se refere a tal regime como "o problema crucial da regulação dos grupos de sociedades" (Marcus LUTTER), não falta mesmo quem, proveniente da tradição da "Common Law", vá mesmo mais longe, referindo-se àquele "como um dos grandes problemas irresolvidos do moderno direito societário" (Clive SCHMITTHOFF).

Oliveira (1979, p.157), por sua vez, depara-se com a dúvida acerca da possibilidade de se conferir personalidade jurídica ao grupo da seguinte forma:

Na medida em que se admite a dependência de uma sociedade a uma outra, como é o típico caso dos grupos centralizados e de subordinação, é de se questionar se ao grupo poderia ser conferida uma personalidade jurídica distinta das suas componentes, tendo em vista que, por sua característica econômica, está-se diante de uma verdadeira mega-sociedade ou até de uma "fusão extraordinária" de sociedades.

É nesse diapasão que se tenta definir e delimitar o âmbito da responsabilidade dos grupos sociais. Diante de inúmeras divergências doutrinárias, jurisprudenciais e, até mesmo, legislativas $^{10}$, é, hoje, possível identificar três tipos de estratégias regulatórias fundamentais no âmbito mundial, sendo elas: a estratégia tradicional da "autonomia societária"; a estratégia revolucionária do "controle societário"; e a estratégia mitigada do chamado "modelo dualista" alemão" (ANTUNES, 2008, p.40).

Sobre a definição de Antunes, tem-se que a estratégia tradicional da autonomia societária consiste na posição daquelas ordens jurídico-societárias que resolvem os problemas da responsabilidade da empresa plurissocietária com base no dogma fundamental da autonomia societária (“entity law”). Dessa forma, um ente societário pertencente a um grupo não pode ter a respectiva sociedade-mãe responsabilizada pelos atos ou débitos dos demais entes societários integrados no mesmo perímetro grupal, visto que tais entes constituem pessoas coletivas juridicamente independentes (ANTUNES, 2008, p.40).

O modelo estratégico, por sua vez, é aquele que tem por base a realidade fundamental do controle societário, ou seja, a responsabilidade societária está ligada ao fato de que a sociedade mãe deverá ser responsável por todas as dívidas ou todos os passivos das respectivas sociedades-filhas, pela simples e decisiva razão de que a primeira controla a vida e

\footnotetext{
${ }^{10}$ Apesar do caráter globalizado conferido aos grupos econômicos, não é raro perceber essas diferenças sobre o mesmo tema em diversos países.
}

Revista Brasileira de Direito Empresarial -le-SSN: 2526-0235| Curitiba | v. 2 | n. 2 | p. 42 - 59 | Jul/Dez. 2016. 
a gestão empresarial das últimas, formando, assim, uma empresa unitária (ANTUNES, 2008, p.42-43).

Por fim, o regime de responsabilidade da empresa plurissocietária resultante do modelo dualista decorria automaticamente do acomodamento ou integração da realidade grupal em um destes dois modelos formais de grupo: ou um sistema de compensação global e automático do passivo das filiais, estabelecido "ex ante", no caso dos grupos de direito (em que a sociedade-mãe viu reconhecido um poder legal de controle sobre a condução dos negócios sociais daquelas), ou um sistema de compensação pontual e casuístico, apenas constatável "ex post", no caso das filiais dos grupos de fato (na qual se supõe que as sociedades-filhas permanecem autônomas na condução dos seus negócios, razão pela qual a sociedade-mãe apenas poderá ser obrigada a compensar aqueles prejuízos patrimoniais que hajam concretamente resultado para as filiais em consequência do uso ilegítimo por aquela da sua influência dominante) (ANTUNES, 2008, p.46).

O Brasil adota o modelo dualista, proposto por Antunes, ao fazer uma diferenciação entre a responsabilidade das sociedades que compõem os grupos de fato e de direito. Para Lima e Miranda (2009), as sociedades de fato, que estiverem agrupadas, poderão ser demandadas em ações judiciais em caso de favorecimento mútuo ${ }^{11}$ entre elas. Já as plurissociedades de direito, não possuem tais restrições, ao passo que a controladora pode impor às controladas políticas administrativas, financeiras, operacionais e, até mesmo, subordiná-las aos interesses de dadas sociedades em detrimento de outras pertencentes do mesmo grupo, desde que de acordo com a convenção e a lei.

No que tange à solidariedade entre as plurissociedades de fato, Castro (s/d, p.14) acredita que ela não deva existir em função da ausência de regulamentação e da preservação da personalidade jurídica, como se vê:

Diante da preservação da personalidade jurídica e, consequentemente, da autonomia patrimonial e administrativa das sociedades integrantes de um grupo econômico de fato, e da ausência de previsão legal que lhes imponha a solidariedade pelas obrigações contraídas apenas por uma delas, a princípio, somente a sociedade que vier a se vincular diretamente junto a terceiros é que responderá pelas obrigações

\footnotetext{
11 A Lei das Sociedades por Ações prescreve no Art. 246, para as sociedades agrupadas de fato, que os administradores serão responsabilizados por qualquer favorecimento de uma sociedade a outra; e tal favorecimento - pela frequência e facilidade com que ocorre em prejuízo dos minoritários - está sujeito a sanções e procedimento especial (art. 247 e seus $\S \S)$.
}

Revista Brasileira de Direito Empresarial -le-SSN: 2526-0235| Curitiba | v. 2 | n. 2 | p. 42 - 59 | Jul/Dez. 2016. 
contraídas perante os mesmos, não havendo que se falar, portanto, em solidariedade entre as sociedades integrantes do grupo.

Alguns enunciados normativos, entretanto, optaram por não se ater à diferença entre a responsabilidade dos grupos de fato e de direito e impõem a solidariedade como um dever. Apesar de existirem algumas divergências, "via de regra, deveria inexistir solidariedade entre as sociedades do grupo de fato, salvo por sanções decorrentes de infração de ordem econômica, nas obrigações previdenciárias ou nas dívidas trabalhistas" (LIMA; MIRANDA, 2009 , p.04). No Brasil, jurisprudencialmente ${ }^{12}$, têm-se inclinado para responsabilizar integralmente o grupo econômico, independente dele ser de fato ou de direito.

\section{ASPECTOS RELANTES DA RECUPERAÇÃO JUDICIAL EM GRUPOS}

A despeito das questões discutidas sobre grupo econômico, tem-se perguntado sobre a possibilidade de o grupo econômico conjuntamente formular um único pedido de recuperação judicial, ou seja, sobre a possibilidade de um litisconsórcio ativo nesse pedido. A legislação comercial não trata desse assunto, é completamente omissa. Cabe aos juízes, portanto, até se ter uma novidade legislativa, a decisão sobre se entende viável ou não a formação desse litisconsórcio.

Como já mencionado, sobre a responsabilidade plurissocietária, a jurisprudência tem se manifestado no sentido de responsabilizar de modo unificado o grupo. Diante dessa posição, percebe-se a inclinação judicial para deferir o litisconsórcio ativo no pedido de recuperação judicial $^{13}$, visto que, se uma empresa do grupo econômico passa por uma crise financeira, o grupo teria responsabilidade para manter a empresa com dificuldades em funcionamento, ou seja, o grupo teria responsabilidade também com relação aos credores da empresa em crise. Nesse sentido, tem-se a sentença do Juiz de Direito Daniel Carnio Costa, no pedido do grupo OAS (e-SAJ, 2015, fls.3329),

O litisconsórcio ativo também está bem justificado, na medida em que todas as empresas atuam de forma sistêmica e integram um mesmo grupo econômico. Nesse sentido, a preservação dos benefícios sociais e econômicos decorrentes da atividade empresarial saudável (que é o objetivo do presente processo), será melhor atendida se enfrentada a situação de crise de maneira global, considerando as empresas

\footnotetext{
12 Apelação Cível APC 20150310162057 (TJ-DF); Agravo de Instrumento AGI 20150020177904 (TJ-DF); APL 03566913620128190001 RJ 0356691-36.2012.8.19.0001 (TJ-RJ); Apelação Cível AC 70054612742 RS (TJRS).

${ }^{13}$ Como se percebe nos pedidos aceitos do Grupo OAS, Grupo Bom Jesus e Grupo Oi, dentre outros.
} 
integrantes do grupo econômico, e não isoladamente. A questão relacionada à incorporação da OAS Investimentos pela OAS S/A (que é objeto de discussão judicial em andamento) é irrelevante para os fins do presente procedimento, na medida em que tanto o patrimônio, quanto o passivo de ambas estão sujeitos ao processo de recuperação judicial. Confirmando-se ou não a incorporação, o fato é que os credores de ambas estarão sujeitos à recuperação judicial do grupo econômico e o patrimônio de ambas estará integralmente sujeito ao cumprimento dos objetivos do presente.

A aceitabilidade da formação do litisconsórcio ativo prece que está pacificada na jurisprudência e, de fato, pode trazer benefícios a uma efetiva recuperação da empresa em crise, tendo em vista que uma empresa do grupo, em uma situação financeira melhor do que outra, pode ajudar a compensar os passivos daquela em uma situação pior. Tende-se a diluir o ônus de uma por todas, como uma tentativa de manter o grupo inteiro em boa situação.

Essa aceitação, todavia, cria problemas quando se pensa no plano de recuperação judicial e pode vir a causar um aumento nos custos de transação. Em relação àquele, porque, sendo em conjunto, não se consegue visualizar quais das empresas arroladas efetivamente passam por uma crise econômico-financeira, além dificultar, para o próprio credor, um conhecimento sobre se o plano está em condições de preservar o seu crédito de forma consistente ou não.

Quanto ao aumento dos custos de transação ${ }^{14}$, este pode acontecer, tendo em vista que as informações não estão claras para todo o grupo, já que elas trabalham de forma independente, podendo fazer com que uma empresa arque com as responsabilidades pertencentes à outra do mesmo grupo. Nesse sentido Machado, Oliveira e Campos Filho (2004, p.02) escrevem:

A escassez de informações, a instabilidade ambiental, a possibilidade de os atores serem oportunistas e a pequena margem de negociação entre o binômio clientefornecedor em certas situações mercadológicas, portanto, criam falhas de mercado (PFEFFER, 1992), as quais são as fontes para o surgimento dos custos de transação. (Grifo próprio)

\footnotetext{
${ }^{14}$ A abordagem da Teoria dos Custos de Transação sustenta, de forma simplificada, que as relações de mercado e as tomadas de decisão dos agentes levam em conta outros elementos que não somente os custos econômicos envolvidos nas transações. A teoria nascida a partir de COASE, aplicada aos procedimentos de abertura de novas firmas permite a visualização da existência de pontos de tensão entre o desenvolvimento da iniciativa privada e a estrutura do Estado a qual eles são submetidos.
} 
Coase (1960, p.06) dissertando sobre os custos sociais provenientes da utilização de direitos pelos indivíduos, apresenta interessante passagem tratando sobre os custos de transação:

\begin{abstract}
De modo a realizar as transações, necessita-se descobrir quem é a outra parte com a qual se deseja negociar, informar as pessoas acerca da disposição de negociar e em que termos, conduzir as negociações em direção à barganha, formular o contrato, empreender meios de inspeção para se assegurar que os termos do contrato estão sendo cumpridos, e assim por diante. Tais operações são, geralmente, extremamente custosas, suficientemente custosas para evitar a ocorrência de transações que seriam levadas a cabo em um mundo em que o sistema de preços funcionasse sem custos.
\end{abstract}

Se tal fato ocorre, ela poderá, a partir disso, enfrentar uma crise econômico-financeira ou, na tentativa de se precaver disso, ela aumentará os custos de transação para diminuir os riscos. Assim, o Estado estaria produzindo um incentivo negativo para a produção de grupos para o mercado globalizado. Corroborando esse posicionamento Freitas e Timm (2010, p.442):

\begin{abstract}
A percepção de que as instituições importam e que a conformação das regras formais e informais de uma determinada sociedade podem influenciar a atividade econômica redirecionam o interesse da Ciência Econômica para o Direito - aqui entendido como conjunto de princípios e regras estatais e sociais reconhecidas pelos órgãos de produção normativa (cortes de justiça, agências reguladoras, instituições de assentamentos de práticas e usos mercantis). Nesse contexto, a Ordem Jurídica passa a ser percebida como tendo papel fundamental junto ao mercado e ao desenvolvimento econômico, servindo para reduzir ou minimizar os custos das transações.
\end{abstract}

Nesse diapasão, adaptando essa teoria ao caso brasileiro, sustenta Filho (2008, p.09) que, no Brasil, esses custos são demasiadamente elevados, sendo os elementos formalidade e informalidade os responsáveis em grande parte pela existência desses custos. O primeiro é caracterizado pela burocracia excessiva e, consequentemente, pela ineficiência, e a segunda é considerada responsável por criar ambientes de incerteza às relações do mercado. Esse quadro reflete diretamente no desenvolvimento econômico do país.

Sendo assim, uma alternativa, para viabilizar o litisconsórcio ativo na recuperação judicial e evitar o aumento dos custos de transação, seria a possibilidade de que cada empresa integrante do grupo econômico formulasse seu próprio plano de recuperação judicial. Nele, deveriam constar, de forma individual e específica, os créditos exclusivos de cada empresa e não em junção com os créditos de todas as outras. Com isso, evitar-se-ia, também, uma confusão aos credores, permitindo, portanto, que eles saibam, de forma bastante clara, quais 
as modificações dos seus créditos e a nova forma de pagamento, podendo, assim, votar pela aprovação ou não do plano mais conscientemente.

\section{CONCLUSÃO}

Após ter sido mostrado como se efetua o deferimento do plano de recuperação judicial e os seus aspectos mais importantes, passou-se a analisar o que seria grupos econômicos e as teorias que versavam sobre o tipo de responsabilidade imputada ao grupo.

O fato é que, apesar de existir a diferenciação entre grupos de fato e de direito, os julgadores não podem deixar de reconhecer a existência dos grupos no mundo fático. Esse reconhecimento desemboca na necessidade de se estabelecer critérios mínimos que se consiga definir a responsabilidade de cada sociedade pertencente ao grupo econômico, sob pena de desestimular a criação destes.

Atualmente, tem sido muito comum a aceitação do pedido de recuperação judicial da sociedade em grupo. A jurisprudência tem entendido que, caso se considere o grupo em sua totalidade, a recuperação é mais viável, pelo fato de que uma empresa, que esteja saudável, poder vir a responder por uma que está em crise, ou seja, pensa-se na crise de uma maneira global e não individual.

Ora, se, por um lado, é certo que a atividade econômica globalizada não pode abrir mão da formação de conglomerados econômicos, por outro, é indubitável que os credores não podem ficar descoberto, sem tutela legal dos seus direitos. Por esse motivo, entende-se pela viabilidade da recuperação judicial em grupo. Acredita-se, todavia, que seria mais prudente que cada empresa do grupo, que consta como polo ativo do pedido de recuperação judicial, depois de deferido o processamento dela, apresentasse seu próprio plano. Essa medida faria com que a situação econômica de cada empresa, separadamente, fosse minunciosamente analisada. Com uma boa avaliação individual dessa circunstância, têm-se chances mais reais de recuperação, além de trazer uma maior visibilidade para o credor da condição financeira de cada empresa e do grupo em sua totalidade.

Diante dessa medida, também se conseguirá verificar, mais concretamente, como uma empresa do grupo poderá ajudar com o passivo da outra, sem prejudicá-la, ou seja, sem fazer 
com que uma empresa sadia venha a se tornar insolvente por causa das dívidas de outra, evitando, assim, o aumento dos custos de transação.

\section{REFERÊNCIAS BIBLIOGRÁFICAS}

ANTUNES, José Engrácia. Estrutura e Responsabilidade da Empresa. In: Revista Direito GV, São Paulo, n.2, v. 1. jan./dez. 2005.

BRASIL. Lei 11.101/2005 - Lei de Falência e Recuperação de Empresas, 2005.

BRASIL. Lei 6.404/1976 - Lei das Sociedades Anônimas, 1976.

Tribunal de Justiça do Estado de São Paulo. Pedido de Recuperação Judicial. Sentença em Processo Digital $n^{\circ}$ 1030812-77.2015.8.26.0100. Requerente: OAS S/A e outros Requerido: OAS S/A e outros. Juiz: Juiz de Direito: Dr. Daniel Carnio Costa. SP, 01 abril de 2015. Disponível em: <http://www.oas.com/oas-com/recuperacao-judicial/documentos.htm>

Superior Tribunal de Justiça. Recurso Especial no 1.266.666 - SP (2009/01969409). Recorrente: Carlos Masetti Júnior e Outro (s), Recorrido: Petroforte Petróleo Brasileiro S/A - Massa Falida e outros. $3^{\text {a }}$ Turma do STJ. Rel. Ministra Nancy Andrighi. DJe, 09 de agosto de 2011. Disponível em: https://ww2.stj.jus.br/processo/revista/documento/mediado/?componente=ITA\&sequencial=1 079486\&num_registro=200901969409\&data $=20110825 \&$ formato=PDF $>$.

BERLE, Adolf A.; MEANS, Gardiner C..The modern corporation and private property. New Brunswick, NJ: Transaction Publishers, 1932.

CASTRO, Marina Grimaldi de. As definições de grupo econômico sob a ótica do direito societário e do direito concorrencial: entendimentos doutrinários e jurisprudenciais acerca da responsabilidade solidária entre seus componentes. Disponível em:< http://www.publicadireito.com.br/artigos/?cod=af3b0930d888e15a > . Acesso em: 09 de jan. 2017.

CHAMPAUD, Claude. Le pouvoir de concentration de la société par actions. In: Revue internationale de droit comparé. Vol. 17 N4, Octobre-décembre 1965. p. 969.

COASE, Ronald. A firma, o mercado e o direito. In: (Coleção Paulo Bonavides). O problema do custo social. Coord. Rio de Janeiro: Forense, 2016.

COELHO, Fábio Ulhoa. Curso de Direito Comercial: direito de empresa. 12 ed. São Paulo: Saraiva, 2011. V.3.

FREITAS, Fabrício Loureiro de Carvalho; TIMM, Luciano Benetti. A abertura de novas empresas no brasil e a teoria dos custos de transação. Disponível em: < http://www.publicadireito.com.br/conpedi/manaus/arquivos/anais/fortaleza/3692.pdf $>$ Acesso em: 09 jan. 2017.

FILHO, André Franco Montoro; MOSCOGLIATO, Marcelo; PILAGALLO, Direito e Economia: o Diálogo Entre Juristas e Economistas. São Paulo, 2008. 
HOLLANDA, Pedro Ivan Vasconcelos. Os grupos societários como superação do modelo tradicional da sociedade comercial autônoma, independente e dotada de responsabilidade limitada. Dissertação apresentada ao Programa de Pós-Graduação em Direito pela Universidade Federal do Paraná como requisito final para concessão do grau de mestre em Direito da Universidade Federal do Paraná, Curitiba, 2008.

LIMA, Marcelo Cordeiro de. MIRANDA, Maria Bernadete. Grupo de Empresas. In: Revista Virtual Direito Brasil - Volume $3-n^{\circ} 1-2009$. Disponível em: <http://www.direitobrasil.adv.br/arquivospdf/artigos/mar.pdf>.

MACHADO, André Augusto; OLIVEIRA, Marcus Vinicius de Souza Silva; CAMPOS, José Raymundo Ribeiro Filho. Teoria dos custos de transação: um estudo multi-casos de empresas integradas verticalmente. In: XI SIMPEP - Bauru, SP, Brasil, 08 a 10 de novembro de 2004. Disponível em: < http:// www.simpep.feb.unesp.br/ >

MAMEDE, Gladston. Direito empresarial brasileiro: empresa e atuação empresarial. 6 ed. São Paulo: Atlas, 2012. v.1.

, Gladston. Direito empresarial brasileiro: falência e recuperação de empresa. 6 ed. São Paulo: Atlas, 2012. v.4.

MATOS, Liliane Gonçalves. Governança corporativa e as sociedades familiares. Disponível em: <http://www.unifor.br>. Disponível em: dez. 2016. Acesso em: jan. 2017.

OLIVEIRA, José Lamartine Corrêa. A Dupla Crise da Pessoa Jurídica. São Paulo: Saraiva, 1979.

REQUIÃO, Rubens. Curso de Direito Comercial. 30a ed. São Paulo: Saraiva, 2013.

SABAGE, Fabrício Muniz. Grupo de sociedades e consórcios. In: Jus Navigandi, Teresina, n. 53, ano 6. jan. 2002. Disponível em: <http://jus.com.br/artigos/2518>. 